\title{
Genetic variability analysis of faba bean accessions using Inter-simple sequence repeat (ISSR) markers
}

\author{
María E. Salazar-Laureles ${ }^{1}$, Delfina de J. Pérez-López ${ }^{1 *}$, Andrés González-Huerta ${ }^{1}$, \\ Luis M. Vázquez-García ${ }^{2}$, and Ernestina Valadez-Moctezuma ${ }^{3}$
}

Faba bean crop (Vicia faba L.) is important in Mexico, it is a legume rich in protein and its market price is higher than those of maize and bean; however, in recent years there has been a significant decline in its performance. The aim of this study was to determine the genetic variability and analyze the relationship between 39 faba bean accessions using inter simple sequence repeats (ISSR) markers. Accessions of faba bean were collected according to their best phenotypic characteristics, later they were molecularly characterized. With the obtained band registration, a binary data matrix was built to perform the corresponding statistical analysis. The utilized ISSR markers produced 142 fixed and repeatable bands, of which 134 were polymorphic. The values of resolution power (Rp), polymorphic information content (PIC), and marker index (MI), respectively indicated that primer 848 was the most efficient to analyze genetic variability with values of $12.8,0.40$, and 8.06 , respectively, followed by primers 857 and ISSR2M. Genetic distances oscillated between 0.38 and 0.83 , and verified the groupings observed in the dendrogram, which indicates high variability at the level of DNA among the analyzed genotypes, observing six defined groups according to UPGMA analysis. In the analysis of main components the registered groupings were determined by the origin of the gathering. The use of ISSR markers was efficient to characterize at the level of DNA the assessed bean accessions, indicating the existence of variability, the identified contrasting accessions can be utilized in genetic improvement programs aimed at solving the needs of the producers.

Key words: Genetic variability, Mexico, molecular characterization, Vicia faba.

\section{INTRODUCTION}

Cultivation of fababean (Viciafaba L.) is importantbecause its high content of protein, ability to fix atmospheric $\mathrm{N}$ and improve soils, among others, is globally recognized and has been profusely documented (Maalouf et al., 2011; Wang et al., 2012). In Mexico, faba bean is cultivated in the High Valleys mainly in the states of Puebla, Mexico, Tlaxcala, Michoacan, and Hidalgo. It is an introduced species (Cubero y Moreno, 1983) and is considered an alternative cultivation with economic potential, as within the last $10 \mathrm{yr}$ dry faba bean reached market prices between 4 and 5 USD per kilogram, superior to those of maize, wheat, and other legumes. However, in recent decades the production has noticeably decreased, mainly due to

${ }^{1}$ Universidad Autónoma del Estado de México, Centro de Investigación y Estudios Avanzados en Fitomejoramiento, El Cerrillo, Piedras Blancas, Toluca, México.

*Corresponding author (djperezl@uaemex.mx).

${ }^{2}$ Universidad Autónoma del Estado de México, Centro Universitario Tenancingo, km 1.5 carretera Tenancingo-Villa Guerrero, México.

${ }^{3}$ Universidad Autónoma de Chapingo, Laboratorio de Biología Molecular del Departamento de Fitotecnia, km 38.5 Carretera México-Texcoco, Chapingo, México.

Received: 12 July 2014.

Accepted: 26 November 2014.

doi:10.4067/S0718-58392015000100017 conditions of biotic and abiotic stress, so it is necessary to generate materials that counteract side effects; to do so, it is necessary to learn the degree of diversity and relation between accessions by means of characterization, not only agromorphological but also at molecular level, which in our country is incipient and necessary.

Duc et al. (2010) mention that at global level faba bean is only represented in herbarium collections and germplasm banks, so genetic resources represented through wild species, cultivated plants, local accessions, varieties, hybrid lines, and elite lines are important as gene sources. So when a germplasm, diversity and relationship between materials are unknown; characterization of genetic variability and selection of population are important in the efficiency of breeding programs (Alghamdi et al., 2012a).

Even if there is a taxonomic relation between faba bean cultivars according to van de Ven et al. (1993) and studies of agromorphological characterization which have served to learn important aspects of the cultivation (Terzopoulos et al., 2003; 2004; Ahmed et al., 2010; Vörösváry et al., 2011; Yahia et al., 2012), these present certain limitations, since characterizations may have been affected by the stage and development of the plant, environmental influence, agronomic management or else, reveal scarce genetic variability.

Alghamdi et al. (2012a) comment that the genetic diversity of faba bean has been studied with different 
molecular markers, as it is reported by Link et al. (1995), who studied the genetic variability of accessions of faba bean from the Mediterranean Sea and Europe by means of Random Amplified Polymorphic DNA, detecting variability; Kwon et al. (2010) analyzed the genetic diversity and relation between 151 accessions by means of Target Region Amplification Polymorphism (TRAP) finding $55.2 \%$ of polymorphism, sufficient to classify the genotypes; Liu and Hou (2010) studied the genetic diversity of germplasm from Western China by means of Amplified Fragment Length Polymorphism (AFLP) markers finding seven groups that represented $80 \%$ of the assessed genetic information. Gong et al. (2010) generated and characterized 11 new EST type sequences derived from faba bean microsatellites; in like manner, Gong et al.(2011) analyzed the genetic diversity of 5031 faba bean accessions from Europe and China, indicating that only $8.36 \%$ of the sequences had Simple Sequence Repeats (SSR); Ouji et al. (2012) examined nine populations of faba bean from Tunisia by means of Simple Sequence Amplified Polymorphism (SSAP), finding broader diversity in the populations than between them; Alghamdi et al. (2012b) studied 58 faba bean genotypes using Sequence Related Amplified Polymorphism (SRAP), detecting broad genetic variability between the assessed accessions; Akash and Myers (2012) developed Expressed Sequence Tags and Simple Sequence Repeats (EST-SSRs) to validate the diversity analysis of 20 faba bean populations from Jordan; Ma et al. (2013) used SSR markers to produce related maps between faba bean varieties native to China, these markers can be applied in Quantitative Trait Loci (QSL) and selection of assisted markers.

However, Alghamdi et al. (2012a) indicate that Inter Simple Sequence Repeats (ISSR) have been efficient in the study of genetic diversity and the relation between faba bean populations. Using this sort of markers, Wang et al. (2012) analyzed 802 faba bean accessions from China and other parts of the world, they found well-defined groupings of accessions according to the geographic region these accessions came from; AbdelRazzak agree et al. (2012) studied 10 faba bean varieties from Egypt finding differences between cultivars; Alghamdi et al. (2011) assessed 34 faba bean populations detecting variability related to the gathering sites; finally, Terzopoulos and Bebeli (2008) analyzed the genetic diversity of 20 local populations from the Mediterranean, finding high variation levels in them and at least two genetically different groups.

Due to the agronomic and economic interest this species represents, the objective of this work was to determine the genetic variability and relationship between 39 faba bean populations by means of ISSR molecular markers, in views of identifying and selecting genetically contrasting accessions. The results of this work will allow using the detected genetic variability and incorporating it in current genetic improvement programs, which consist in phenotyping and genotyping, schemas aimed at increasing production, generating resistance or tolerance to biotic and abiotic stress, and even creating high-performing and stable materials suitable for various environmental conditions.

\section{MATERIALS AND METHODS}

\section{Vegetal material}

In this study we used seeds from 35 faba bean populations, collected because of their best agromorphological characteristics in 12 municipalities of the State of Mexico, and four varieties generated by the Institute of Agricultural, Aquaculture and Forestal Research and Training of the State of Mexico (ICAMEX), namely: 'San Isidro' (P29), 'Monarca' (P30), 'Diamante' (P31), and 'San Pedro' (P32). The identification code, geographic origin, gathering place, seed size and color of the 39 assessed accessions, altitude and geographic coordinates of the collection sites are summarized in Table 1 .

\section{DNA extraction and ISSR analysis}

Three grams of fresh foliar tissue from seedling of 14 $\mathrm{d}$ of age, healthy and without mechanical damage were selected at random out of a group of ten and weighed for each of the 39 populations. DNA extraction was carried out according to the sodium dodecyl sulfate method by Dellaporta et al. (1983) with lesser modifications, such as the addition of $0.5 \mathrm{mM}$ ascorbic acid, as suggested by Hoelzel (1992) to reduce oxidation. The quality of DNA was evaluated by means of electrophoresis in agarose gel at $0.8 \%$. The utilized oligonucleotides belong to a set of 100 ISSR molecular markers "UBC primer set 100/9" of British Columbia University; of these 40 were evaluated. The ISSR-PCR reactions were performed using $25 \mu \mathrm{L}$ reaction mixture, containing $5.2 \mu \mathrm{L}$ water, $10 \mu \mathrm{L} 0.2 \mathrm{mM}$ dNTP's, $2.5 \mu \mathrm{L}$ Tris H-Cl pH $810 \mathrm{X}$ buffer, $1.5 \mu \mathrm{L} 3 \mathrm{mM}$ $\mathrm{MgCl}_{2}, 3 \mu \mathrm{L}$ primer at a concentration of $10 \mathrm{ng} \mu \mathrm{L}^{-1}, 0.3$ $\mu \mathrm{L} 1.5 \mathrm{U}$ of Taq polimerase enzyme, and $2.5 \mu \mathrm{L}$ template DNA at a concentration of $10 \mathrm{ng} \mu \mathrm{L}^{-1}$ DNA.

Amplifications were carried out in a TECHNE thermal cycler (TC-412, Bibby Scientific Limited, Stone, Staffordshire, UK) considering a pre-denaturalization cycle at $93{ }^{\circ} \mathrm{C}$ for $20 \mathrm{~s}$, followed by 40 cycles for the denaturalization stage at $94{ }^{\circ} \mathrm{C}$ for $20 \mathrm{~s}$; one aligning phase at temperatures defined according to the primer to amplify for $1 \mathrm{~min}$ and a polymerization stage at $72{ }^{\circ} \mathrm{C}$ for $20 \mathrm{~s}$; finally an additional cycle to end up polymerization at $72{ }^{\circ} \mathrm{C}$ for $6 \mathrm{~min}$. The products of the amplification of the assessed primers were separated in a horizontal electrophoresis chamber (SGV-2626T-02, CBS Scientific, San Diego, California, USA) in ultrafine agarose gels at $2 \%$. Later on, they were developed in a solution with $0.5 \mu \mathrm{g} \mathrm{mL}^{-1}$ of ethidium bromide and finally visualized and analyzed in a high-performance UV transilluminator 
Table 1. Identification code, seed characteristics, gathering place, altitude and geographic coordinates of the 39 assessed accessions.

\begin{tabular}{|c|c|c|c|c|}
\hline Identification code & Size, color of dry seed & Gathering place & $\begin{array}{l}\text { Altitude } \\
(\mathrm{m})\end{array}$ & $\begin{array}{l}\text { Geographic } \\
\text { coordinates }\end{array}$ \\
\hline $\mathrm{P} 1, \mathrm{P} 2, \mathrm{P} 3, \mathrm{P} 4, \mathrm{P} 5, \mathrm{P} 6, \mathrm{P} 8, \mathrm{P} 9$ & Small, yellow head & Acambay & 2440 & $\begin{array}{l}19^{\circ} 57^{\prime} 16^{\prime \prime} \mathrm{N} \\
99^{\circ} 50^{\prime} 39^{\prime \prime} \mathrm{W}\end{array}$ \\
\hline P7 & & Jocotitlán & $2200-3400$ & $\begin{array}{l}19^{\circ} 42^{\prime} 26^{\prime \prime} \mathrm{N} \\
99^{\circ} 47^{\prime} 12^{\prime \prime} \mathrm{W}\end{array}$ \\
\hline $\mathrm{P} 10, \mathrm{P} 11, \mathrm{P} 12, \mathrm{P} 13, \mathrm{P} 14, \mathrm{P} 15, \mathrm{P} 16, \mathrm{P} 17, \mathrm{P} 18, \mathrm{P} 19, \mathrm{P} 34$ & Large, yellow head & Calimaya & 2690 & $\begin{array}{l}19^{\circ} 10^{\prime} 25^{\prime \prime} \mathrm{N} \\
99^{\circ} 37^{\prime} 02^{\prime \prime} \mathrm{W}\end{array}$ \\
\hline $\mathrm{P} 20$ & Large, yellow head & Mexicaltzingo & 2600 & $\begin{array}{l}19^{\circ} 13^{\prime} 15^{\prime \prime} \mathrm{N} \\
99^{\circ} 33^{\prime} 05^{\prime \prime} \mathrm{W}\end{array}$ \\
\hline $\mathrm{P} 23$ & Large, yellow head & Santa Cruz Atizapán & 2600 & $\begin{array}{l}19^{\circ} 09^{\prime} 27^{\prime \prime} \mathrm{N} \\
99^{\circ} 29^{\prime} 19^{\prime \prime} \mathrm{N}\end{array}$ \\
\hline $\mathrm{P} 21, \mathrm{P} 22, \mathrm{P} 24, \mathrm{P} 25, \mathrm{P} 37$ & Large, yellow head & Santiago Tianguistenco & 2622 & $\begin{array}{l}19^{\circ} 10^{\prime} 08^{\prime \prime} \mathrm{N} \\
99^{\circ} 28^{\prime} 01^{\prime \prime} \mathrm{W}\end{array}$ \\
\hline $\mathrm{P} 26, \mathrm{P} 33, \mathrm{P} 35$ & Mid-sized, yellow-light brown head & Toluca & 2680 & $\begin{array}{l}19^{\circ} 17^{\prime} 32^{\prime \prime} \mathrm{N} \\
99^{\circ} 39^{\prime} 14^{\prime \prime} \mathrm{W}\end{array}$ \\
\hline P27 & Mid-sized, yellow-light brown head & Zinacantepec & 1160 & $\begin{array}{l}19^{\circ} 17^{\prime} 00^{\prime \prime} \mathrm{N} \\
99^{\circ} 44^{\prime} 00^{\prime \prime} \mathrm{W}\end{array}$ \\
\hline $\mathrm{P} 28$ & Large, yellow head & Almoloya del Rio & 2610 & $\begin{array}{l}19^{\circ} 10^{\prime} 00^{\prime \prime} \mathrm{N} \\
99^{\circ} 29^{\prime} 00^{\prime \prime} \mathrm{W}\end{array}$ \\
\hline $\mathrm{P} 29, \mathrm{P} 30, \mathrm{P} 31, \mathrm{P} 32, \mathrm{P} 39$ & mid-sized, light brown to brown marbled ${ }^{* *}$ & Metepec & 2635 & $\begin{array}{l}19^{\circ} 15^{\prime} 04^{\prime \prime} \mathrm{N} \\
99^{\circ} 36^{\prime} 17^{\prime \prime} \mathrm{W}\end{array}$ \\
\hline P36 & Iid-sized yellow to, light brown head & Lerma & 2570 & $\begin{array}{l}19^{\circ} 17^{\prime} 05^{\prime \prime} \mathrm{N} \\
99^{\circ} 30^{\prime} 43^{\prime \prime} \mathrm{W}\end{array}$ \\
\hline P38 & Small, yellow to light brown head & San Felipe del Progreso & $2570-2650$ & $\begin{array}{l}19^{\circ} 57^{\prime} 16^{\prime \prime} \mathrm{N} \\
99^{\circ} 50^{\prime} 39^{\prime \prime} \mathrm{W}\end{array}$ \\
\hline
\end{tabular}

(Analytik Jena AG, Jena, Germany). The visualized bands were registered and identified, considering 1 presence and 0 absence.

\section{Data analysis}

Only consistent and reproducible bands were considered to run the corresponding statistical analyses. DNA polymorphic bands were registered as discreet variables considering " 1 " presence and " 0 " absence to construct a binary data matrix. Later on, data were processed in Free Tree statistics software (Version 0.9.1.5 (Pavlicek et al., 1999) to produce a genetic distance matrix using Dice coefficient, also known as the similarity coefficient Nei and Li (1979). The resulting matrix was analyzed according to the Unweighted Pair Group Method with Arithmetic Mean (UPGMA), so as to build a dendrogram with 1000 bootstrap replicates. Tree View software was used to visualize the obtained dendrogram.

The informational certainty of primers to difference between accessions was analyzed by means of the estimation of their Polymorphic Information Content (PIC), Marker Index (MI) and Resolution power (Rp). PIC was calculated using the formula described by Roldán-Ruíz et al. (2000), which is: PIC $i=2 f i(1-f i)$, where $P I C i$ is the polymorphic information content of the first $i, f i$ is the frequency of the present bands, and $(1-f i)$ represents the frequency of the absent bands. Considering that the highest value of PIC for dominant markers is 0.5 according to De Riek et al. (2001). MI was calculated following Prevost and Wilkinson (1999), as $\mathrm{MI}=\mathrm{PIC} \times$ number of polymorphic bands, and Rp according to the formula by Gilbert et al. (1999), $\mathrm{Rp}=\Sigma$ $\mathrm{Ib}$, where $l b$ represents the information of the band, which was calculated with: $\mathrm{Ib}=1-(2 \times|0.5-p|)$, where $p$ is the proportion of accessions that contain bands and $l$ represents the percentage of polymorphic bands (PPB). The origin of the accessions was also considered to examine the potential effect of genetic grouping.

The Principal Component Analysis (PCA) was obtained analyzing the correlation of the binary data matrix in GenAlEx 6.501 software (Peakall and Smouse, 2006 ; 2012) and interpreted according to the three main first coordinates.

\section{RESULTS AND DISCUSSION}

\section{Polymorphism of ISSR markers}

Out of the 40 assessed primers only 12 amplified clear, sharp and reproducible polymorphic bands. The names, nucleotide sequences, alignment temperatures, results of the amplification and polymorphism of the utilized markers are shown in Table 2.

The ISSR primers produced a total 142 fixed and repeatable bands; of which 134 were polymorphic with a banding mean of 19.6 for primers 848, 857, and ISSR-2M; while for the rest the mean of bands was 10.1. The size of bands according to molecular weights marker varied from 400 to $5000 \mathrm{bp}$. The values of Rp, PIC, and MI indicated that primer 848 (Figure 1) was the most efficient to analyze genetic variability with values of $12.8,0.40$, and 8.06 , respectively, followed by primers 857 and ISSR2M, which also showed efficiency in the polymorphic amplicons generated. Such results allow distinguishing that primers 848 and ISSR-2M, amplified 20 and 18 total bands and for both $100 \%$ were polymorphic, these are dinucleotides of (CA) anchored to tetra- and penta-nucleotides, these two primers and 866 are nucleotide sequences, still unreported by other researchers to amplify polymorphic bands in faba bean (Terzopoulos et al., 2004; Abdel-Razzak et al., 2012) had already assessed a similar (CA) 8 G sequence in 
Table 2. Results from amplification and polymorphism of 12 ISSR primers used in this study.

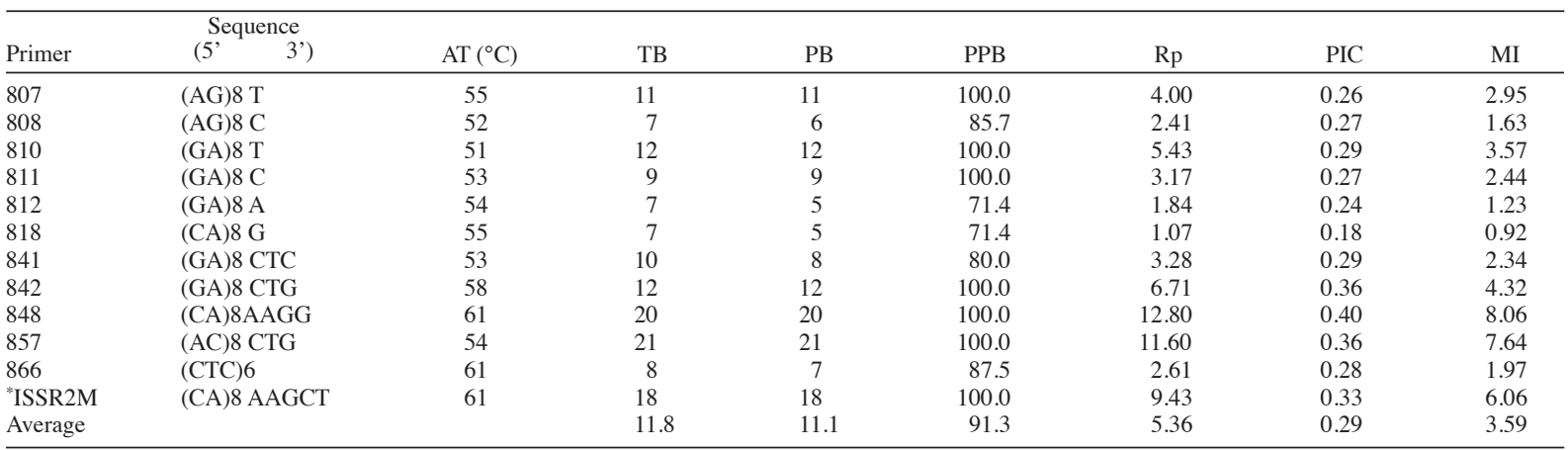

*Primer asked to Sigma-Aldrich Química S.A. de C.V. as num. of oligo 3004066812-020 ISSR with AAGCT ending.

AT: Alignment temperature; TB: total bands; PB: polymorphic bands; PPB: percentage of polymorphic bands; Rp: resolution power; PIC: polymorphic information content; MI: marker index.

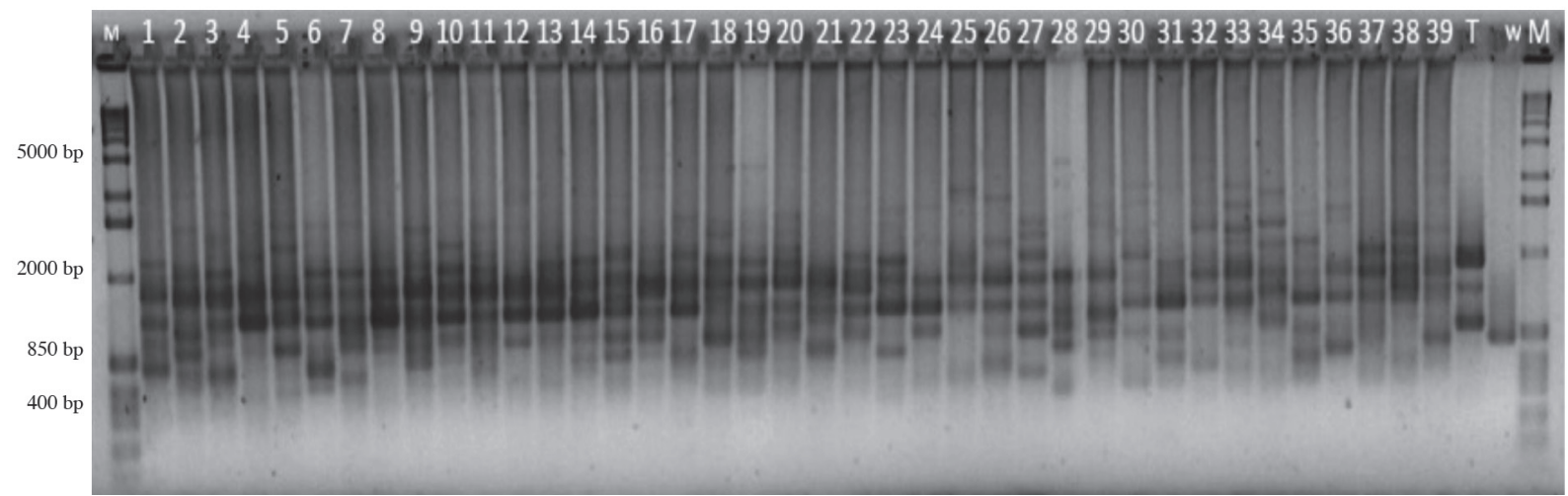

Figure 1. Electrophoresis in agarose gel at $2 \%$ of 39 faba bean populations, using primer ISSR 848. M: Molecular weights marker; T: nonrelated species, W: water.

Greece and Egypt, respectively. By contrast, Terzopoulos and Bebeli (2008), Alghamdi et al. (2011), and Wang et al. (2012) assessing faba bean accessions from Greece, Saudi Arabia, and China, respectively, found higher polymorphism with primers of dinucleotide replications (AG) and (GA) anchored to mononucleotides and trinucleotides; sequences which were also detected in our materials but with fewer total bands. This suggests gene differences between the gathered material assessed in this study and those reported for faba bean cultivars in other countries; such a genetic difference can be attributed to the broad geographic separation there is between the materials. So the primers rich in (CA) may be assessed with faba bean accessions from other continents in order to verify the gene similitude or difference and suggest possible phylogenetic relations, for according to Wang et al. (2012), faba bean accessions from China have their origin in gene sources from Africa, Asia and Europe, while there are no reports about this for accessions from the American continent.

\section{Genetic similarity between accessions}

The genetic relation between accessions was obtained by means of data analysis of ISSR markers, using Dice's similarity coefficient. The matrix of genetic distances showed an average range from 0.38 to 0.83 (Table 3). Which indicates there is high DNA variability between accessions P25 and P37, both belong to the municipality of Santiago Tianguistenco; this suggests they are genetically different materials adapted to the same environment, even though from a different origin. This can be advantageous in programs of genetic improvement, as it is commented by Gresta et al. (2010), the use of this sort of materials might be used to maximize the level of variation and then assess these cultivars in contrasting environments that allow broadening their diversification. The longest distance value was registered between P22 and P23, which suggests great genetic similarity, it can even be suggested that these populations come from one same accession, due to the closeness of the gathering places (Santiago Tianguistenco and Santa Cruz Atizapan) and the mobility of the materials the growers make. Other very closely related accessions were: P10 and P11, P21 and P22, P14 and P23, P2 and P4, P13 and P20. The rest of accessions displayed intermediate similarity levels.

\section{Genetic variability between populations}

The genetic variability described in Table 3 was verified with UPGMA analysis (Figure 2). The dendrogram shows six principal groups (I, II, III, IV, V, VI). Groups 


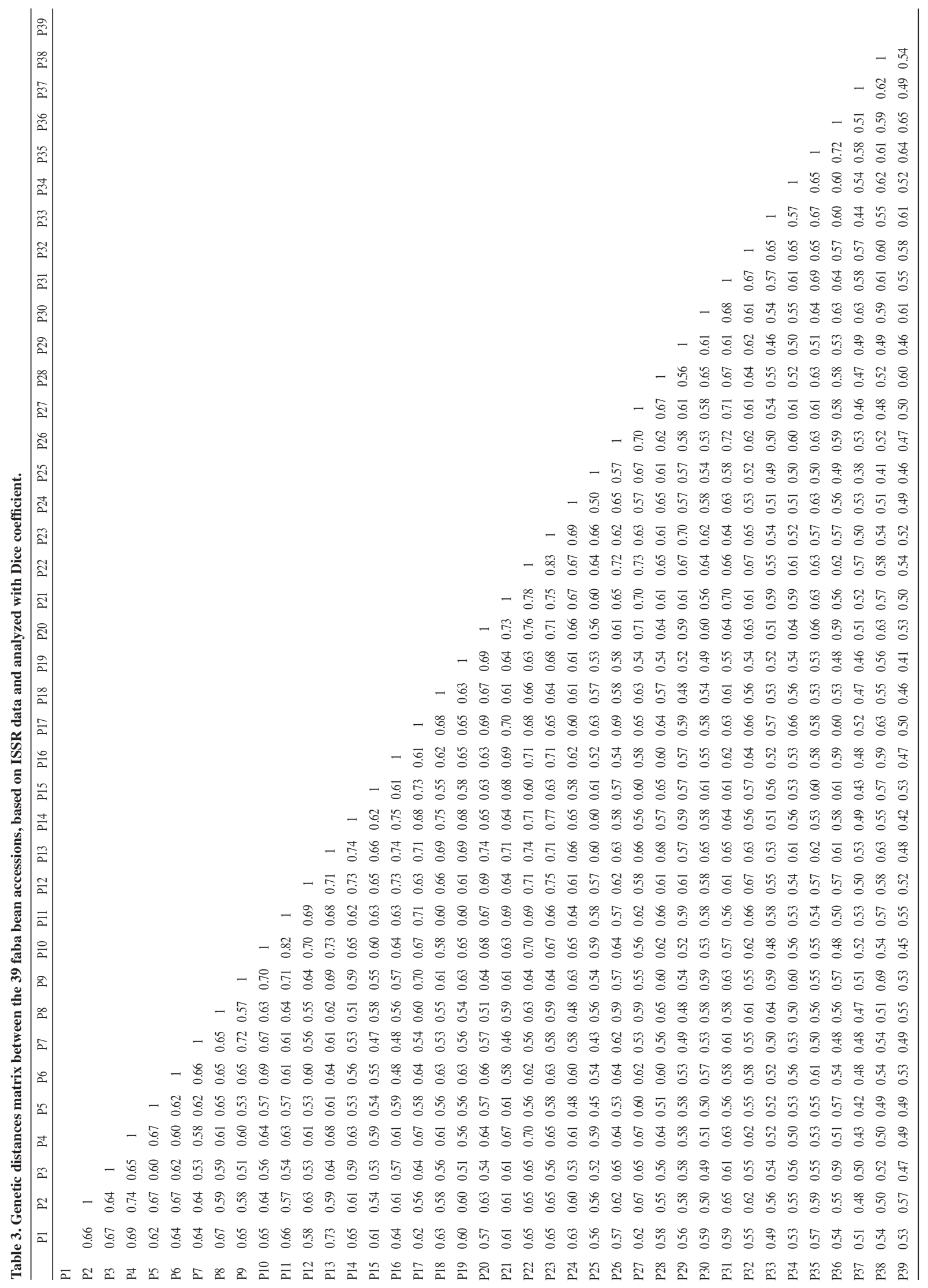




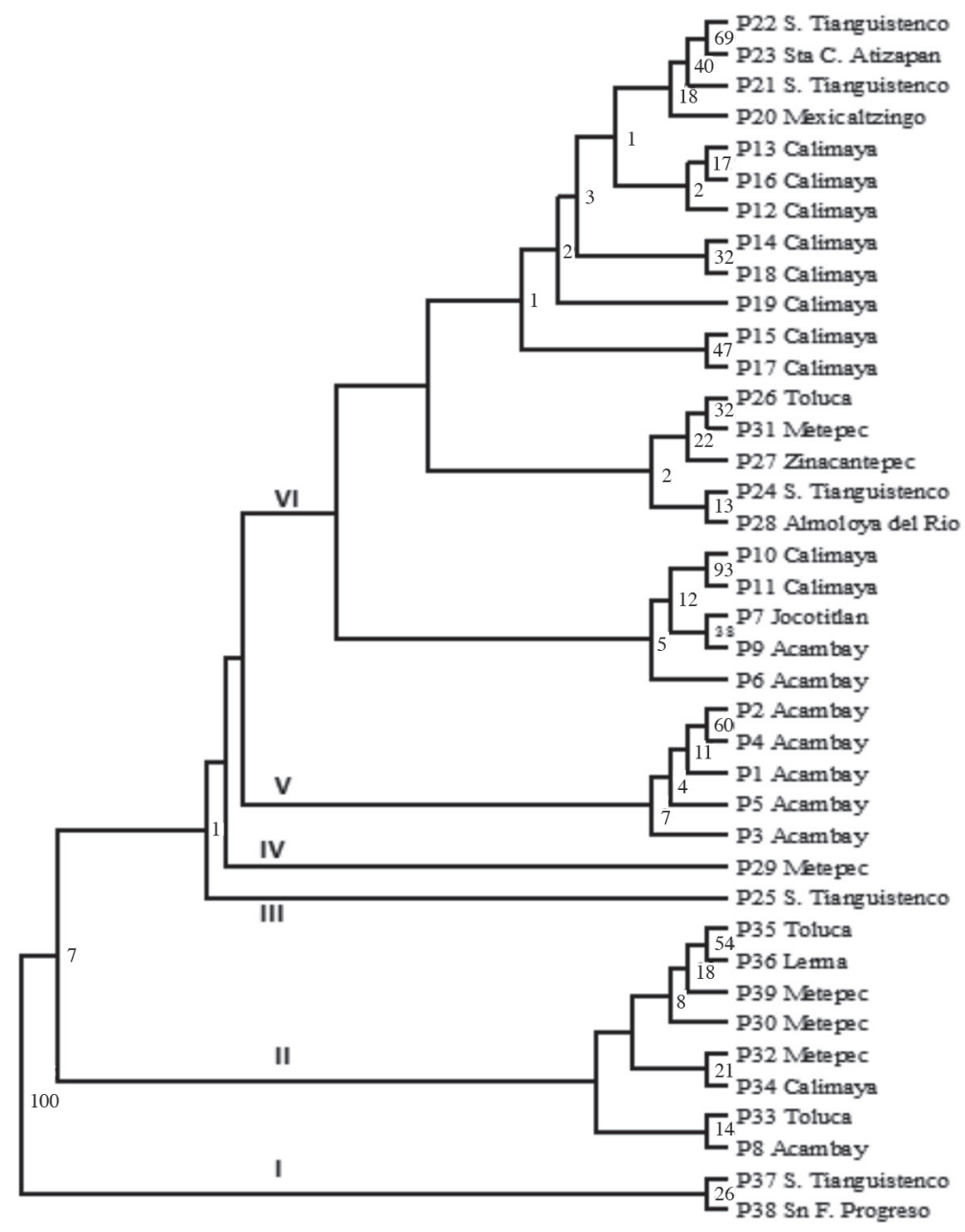

Figure 2. Dendrogram from the UPGMA grouping analysis, using Dice coefficient and ISSR molecular markers in 39 faba bean populations; the number of nodes indicates the percentage obtained with 1000 bootstrapping.

III and IV were integrated by accessions P25 and P29, respectively from Santiago Tianguistenco and Metepec; this indicates these accessions were significantly different at molecular level in relation to all the accessions. The genetic variability observed in accession P25 can be related to a differential response to biotic or abiotic stress, to the agronomic management or else to its facility to adapt to other environments, as it is commented by Duc et al. (2010), variability can be the result from such factors. As for accession P29, it is one of the varieties generated by ICAMEX (2004). The detected genetic variability is attributed to the fact that one of its progenitors has its origin in the Middle East, in Syria, and is characterized by registering the highest yields of green pod and dry grain under adequate management conditions and good development of the cultivation in respect to the rest of varieties (ICAMEX, 2004), so this accession can be used in improvement programs heading to increase yield. Similarly, it was observed that group I comprised only two accessions, P38 and P37, which belong to the geographic places farthest apart in the study zone. It is worth mentioning that P38 is a population in which land is worked above $2500 \mathrm{~m}$ as indicated in Table 1, which suggests that the altitude factor heavily influences on its genetic expression, making it different. These results agree with reports by Terzopoulos and Bebeli (2008) and Wang et al. (2012), who comment that genetic diversity in faba bean is closely associated to the habitat in which it grows, geographic origin, and ecologic distribution. Group II comprehended $60 \%$ of the accessions of the central part, as well as two accessions from the north and south, P8 and P34, respectively. Accession P8, from its grouping, indicates that it is possibly a material with genes adaptive to agro-ecological contrasting conditions; these can be useful to broaden the variability level (Gresta et al., 2010). Group V comprised five accessions that belonged to the municipality of Acambay, located in the north; these accessions are characterized by its 
small seeds and a precocious cycle. Whereas group VI was the largest and grouped $84 \%$ of the accessions from the southeast study zone; in this group the presence of subgroups is distinguishable, possibly from the high mobility of the growers in the zone, since this is the largest zone to buy and sell seeds in the regions. The accessions in this group have a large seed and long cycle. Accessions P6, P7, and P9 from the north, and P26 and P31 were also part of this grouping. Similar results were found by Alghamdi et al. (2011), who comment that the presence of subgroups indicates genetic variability related to adaption to gathering sites and that such differences may be utilized as gene sources to generate lines for the development of synthetic varieties. By and large, the dendrogram allows inferring that groupings were determined partly by its geographic origin, as well as by the genetic differences and similarities accumulated through time, sort of reproduction of faba beans, which are partially allogamous, the constant mobility of the materials the growers make and the facility of the species to adapt to different microenvironments.

The PCA results reveal that the first three axes represent only $33.99 \%$ of the total variability, of these the two first coordinates accumulated $24.41 \%$ of variability and the first $13.45 \%$. Moreover, in this analysis three main groups (A, B, and $\mathrm{C}$ ) and an independent one, comprising P7 (Figure 3), are observed. The dendrogram and PCA of the present study verified similarity between populations and variability was preserved; these results agree with Wang et al. (2012), who also observed congruency between both analyses, perhaps because they worked with faba bean accessions very distant geographically. It is worth mentioning that accessions P25 and P29, which appeared independent in the dendrogram, in PCA they grouped in B; whilst P37 and P38 in A. On its own, group C, held $80 \%$ of the northern populations. Distinguishable is that accession P7 separated from the rest of populations (locating at -7.02, axis 2); a situation that was not observed in the dendrogram, this indicates it is a different material in molecular terms. This accession is cultivated at average altitudes of $2800 \mathrm{~m}$ (Table 1).

Finally, it is indicated that accessions P25, P29, P37, P38, P8, and P7 are molecularly different and can be assessed in the field to determine their agromorphological qualities and determine their agronomic potential. These accessions represent $15.3 \%$ of the total assessed material, nevertheless, this minimal variability is considered sufficient to broaden the genetic base of the species in the highlands of the State of Mexico.

\section{CONCLUSIONS}

Molecular markers ISSR-2M, 848 and 866 are gene sequences that broadened the highest percentage of polymorphic bands for the gatherings of faba bean here analyzed, such sequences might be utilized to genotype accessions from other countries and generate sufficient information to infer possible phylogenetic relations. The use of molecular ISSR markers was efficient to detect differences between the assessed populations, indicating that in $15.3 \%$ of the accessions important genetic variability was registered; this variability can be selected

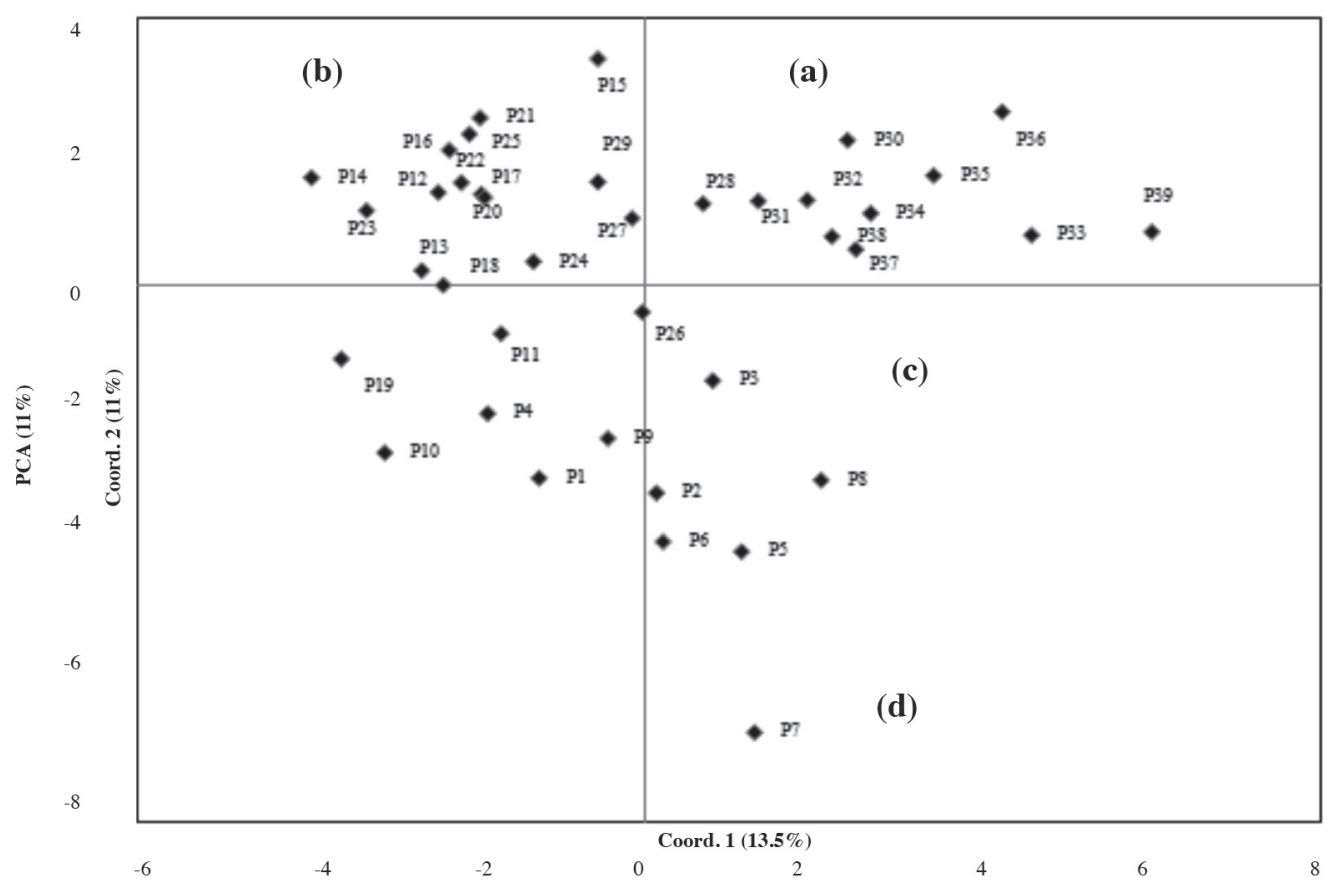

Figure 3. PCA results of the two first discriminating axes for the 39 faba bean accessions produced by 12 ISSR markers. 
and valued in the field to learn their agronomic potential and later incorporation in improvement programs. The experience of the present research allows reflecting on the need to analyze a larger number of faba bean accessions from all over the country in views of broadening the studies of variability at the level of DNA, not only to contribute to genetic improvement, but also to preserve germplasm and create outstanding genotypes for the alimentary industry.

\section{ACKNOWLEDGEMENTS}

The authors are grateful for the financial support to carry out this project to the Universidad Autónoma del Estado de México, México.

\section{LITERATURE CITED}

Abdel-Razzak, H.S., A.M. Alfrmawy, H.M. Ibrahim, and A.A. El-Hanafy. 2012. Genetic diversity in faba bean (Vicia faba L.) using Inter-Simple Sequence Repeat (ISSR) markers and protein analysis. Life Science Journal 9:497-503.

Ahmed, A.M.O., O.Y. Samia, and A.T. Olway. 2010. Performance of faba beans (Vicia faba L.) cultivars grown in new agro-ecological region of Sudan (Southern Sudan). Australian Journal of Basic and Applied Sciences 4:5516-5521.

Akash, M.W., and G.O. Myers. 2012. The development of faba bean expressed sequence tag-simple sequence repeats EST-SSRs) and their validity in diversity analysis. Plant Breeding 131:522-530. doi:10.1111/j.1439-0523.2012.01969.x.

Alghamdi, S.S., S.A. Al Faifi, H.M. Migdadi, M.H. Ammar, and K.H.M. Siddique. 2011. Inter-simple sequence repeat (ISSR)based diversity assessment among faba bean genotypes. Crop Pasture Science 62(9):755-760.

Alghamdi, S.S., S.A. Al-Faifi, H.M. Migdadi, M.A. Khan, E.H. ElHarty, and M.H. Ammar. 2012b. Molecular diversity assessment using sequence related amplified polymorphism (SRAP) markers in Vicia faba L. International Journal and Molecular Sciences 16457-16471. doi:10.3390/ijms131216457.

Alghamdi, S.S., H.M. Migdadi, M.H. Ammar, J.G. Paull, and K.H.M. Siddique. 2012a. Faba bean genomics: current status and future prospects. Euphytica 186:609-624. doi:10.1007/s10681012-0658-4

Cubero, J.I., y N.T. Moreno. 1983. Leguminosas de grano. Ed. Mundi Prensa, Madrid, España.

Dellaporta, S.L., J. Wood, and J.B. Hicks. 1983. A plant DNA minipreparation: Version II. Plant Molecular Biology Reporter 1(4):19-20. doi:10.1007/BF02712670.

De Riek, J., E. Calsyn, I. Everaert, E. Van Bocksteal, and M. De Loose. 2001. AFLP based alternative for the assessment of the distinctness, uniformity and stability of sugar beet varieties. Theoretical and Applied Genetics 103:1254-1256. doi:10.1007/ s001220.100710.

Duc, G., S.Y. Bao, M. Baum, B. Redden, M. Sadiki, M.J. Suso, et al. 2010. Diversity maintenance and use of Vicia faba L. genetic resources. Field Crops Research 115:270-278. doi:10.1016/j. fcr.2008.10.003

Gilbert, J.E., R.V. Lewis, M.J. Wilkinson, and P.S.D. Caligari. 1999. Developing and appropriate strategy to assess genetic variability in plant germplasm collections. Theoretical and Applied Genetics 98:1125-1131. doi:10.1007/s001220051176.

Gong, Y.M., S.C. Xu, W.H. Mao, Q.Z. Hu, G.W. Zhang, J. Ding, et al. 2010. Generation and characterization of 11 novel EST derived microsatellites from Vicia faba (Fabaceae). American Journal of Botany e69-e71. doi:10.3732/ajb.1000166.
Gong, Y.M., S.C. Xu, W.H. Mao, Z.Y. Li, Q.Z. Hu, G.W. Zhang, et al. 2011. Genetic diversity analysis of faba bean (Vicia faba L.) based on EST-SSR markers. Agricultural Sciences in China 10:838-844. doi:10.1016/S1671-2927(11)60069-2.

Gresta, F., G. Avola, E. Albertini, L. Raggi, and V. Abbate. 2010. A study of variability in the Silician faba bean landrace 'Larga di Leonforte'. Genetic Resources and Crop Evolution 57:523-531. doi:10.1007/s10722-009-9490-7.

Hoelzel, A.R. 1992. Molecular genetic analysis of populations: a practical approach. Oxford University Press, New York, USA.

ICAMEX. 2004. Tecnologías de producción del cultivo de haba. Instituto de Investigación y Capacitación Agropecuaria, Acuícola y Forestal del Estado de México (ICAMEX), Toluca, México.

Kwon, S.J., J. Hu, and C.J. Coyne. 2010. Genetic diversity and relationship among faba bean (Vicia faba L.) germplasm entries as revealed by TRAP markers. Plant Genetic Resources: Characterization and Utilization 8(3):204-213. doi:10.1017/ S1479262110000201

Link, W., C. Dixkens, M. Singh, M. Schwall, and A.E. Melchinger. 1995. Genetic diversity in European and Mediterranean faba bean germ plasm revealed by RAPD markers. Theoretical and Applied Genetics 90:27-32. doi:10.1007/BF00220992.

Liu, Y., and W. Hou. 2010. Genetic diversity of faba bean germplasms in Qinghai and core germplasm identified based on AFLP analysis. Legume Genomics and Genetics 1(1):1-6. doi:10.5376/ $\operatorname{lgg} .2010 .01 .0001$

Ma, Y., S.Y. Bao, T. Yang, J.G. Hu, J.P. Guan, Y.H. He, et al. 2013. Genetic linkage map of Chinese native variety faba bean (Vicia faba L.) based on simple sequence repeat markers. Plant Breeding 132:397-400. doi:10.1111/pbr.12074.

Maalouf, F., S. Khalil, S. Ahmed, A.N. Akintunde, M. Kharrat, K.E. Shama'a, et al. 2011. Yield stability of faba bean lines under diverse broomrape prone production environments. Field Crops Research 24:288-294. doi:10.1016/j.fcr.2011.06.005.

Nei, M., and W.H. Li. 1979. Mathematical model for studying genetic variation in terms of restriction endonucleases. Proceedings of the National Academy of Sciences of the United States of America 76:5269-5273. PMC413122.

Ouji, A., S. El Bok, N.H. Syed, R. Abdellaoui, M. Rouaissi, A.J. Flavell, et al. 2012. Genetic diversity of faba bean (Vicia faba L.) populations revealed by sequence specific amplified polymorphism (SSAP) markers. African Journal of Biotechnology 11:2162-2168. doi:10.5897/AJB11.2991.

Pavlicek, A., S. Hrda, and J. Flegr. 1999. Free Tree-Freeware program for construction of phylogenetic trees on the basis of distance data and for bootstrap/jackknife analysis of the tree robustness. Application in the RAPD analysis of the genus Frenkelia. Folia Biology (Prague) 45:97-99.

Peakall, R., and P.E. Smouse. 2006. GENALEX 6: Genetic analysis in Excel. Population genetic software for teaching and research. Molecular Ecology Notes 6:288-295.

Peakall, R., and P.E. Smouse. 2012. GenAlEx 6.5: Genetic analysis in Excel. Population genetic software for teaching and research-an update. Bioinformatics 28:2537-2539.

Prevost, A., and M.J. Wilkinson. 1999. A new system of comparing PCR primers applied to ISSR fingerprinting of potato cultivars. Theoretical and Applied Genetics 98:107-112. doi:10.1007/ s001220051046.

Roldán-Ruíz, I., J. Dendauw, E. Van Bockstaele, A. Depicker, and M. De Loose. 2000. AFLP markers reveal high polymhorphic rates in Ryegrasses (Lolium spp.) Molecular Breeding 6:125-134. doi:10.1023/A:1009680614564.

Terzopoulos, P.J., and P.J. Bebeli. 2008. Genetic diversity analysis of Mediterranean faba bean (Vicia faba L.) with ISSR markers. Field Crops Research 108(1):39-44. doi:10.1016/j.fcr.2007.08.006.

Terzopoulos, P.J., P.J. Kaltsikes, and P.J. Bebeli. 2003. Collection, evaluation and classification of Greek populations of faba bean (Vicia faba L.) Genetic Resources and Crop Evolution 50:373381. doi:10.1023/A:1023962618319. 
Terzopoulos, P.J., P.J. Kaltsikes, and P.J. Bebeli. 2004 Characterization of Greek populations of faba bean (Vicia faba L.) and their evaluation using a new parameter. Genetic Resources and Crop Evolution 51:655-662. doi:10.1023/ B:GRES0000024654.89373.c2.

van de Ven, W.T., N. Duncan, G. Ramsay, M. Phillips, W. Powell, and R. Waugh. 1993. Taxonomic relationships between Vicia faba and its relatives based on nuclear and mitochondrial RFLPs and PCR analysis. Theoretical and Applied Genetics 86:71-80. doi:10.1007/BF00223810.

Vörösváry, G., L. Holly, S. Strajeru, J. Tamás, D. Constantinovici, G. Málnási Csizmadia, et al. 2011. Studies on the variation of agronomic traits in some faba bean (Vicia faba L.) landraces from Romania. Bulletin of University of Agricultural Sciences and Veterinary Medicine. Horticulture 68:279-283. Print ISSN 18435254; Electronic ISSN 1843-5394.
Wang, H.F., X. Zong, J.P. Guan, T. Yang, X.L. Sun, Y. Ma, et al. 2012. Genetic diversity and relationship of global faba bean (Vicia faba L.) germplasm revealed by ISSR markers. Theoretical and Applied Genetics 124:789-797. doi:10.1007/s00122-011-1750-1.

Yahia, Y., A. Guetat, W. Elfalleh, A. Ferchichi, H. Yahia, and M. Loumerem. 2012. Analysis of agromorphological diversity of southern Tunisia faba bean (Vicia faba L.) germplasm. African Journal of Biotechnology 11:11913-11924. doi:10.5897/ AJB11.3366. 